\title{
Clinicopathological Characteristics And Treatment Outcomes Of Breast Cancer Among Adolescents And Young Adults In A Developing Country
}

This article was published in the following Dove Press journal: Cancer Management and Research

\author{
Hikmat Abdel-Razeq $\mathbb{D D}^{1,2}$ \\ Hanan Almasri ${ }^{3}$ \\ Fadwa Abdel Rahman (1D ${ }^{3}$ \\ Hazem Abdulelah' \\ Mahmoud Abu Nasser (D) \\ Mourad Salam' \\ Ammer Al-Dairi (iD ${ }^{3}$ \\ Osama Natour ${ }^{4}$ \\ Dalia Rimawi $\mathbb{D}^{5}$
}

\begin{abstract}
'Department of Internal Medicine, King Hussein Cancer Center, Amman, Jordan; ${ }^{2}$ School of Medicine, University of Jordan, Amman, Jordan; ${ }^{3}$ Department of Radiation Oncology, King Hussein Cancer Center, Amman, Jordan; ${ }^{4}$ Department of Surgery, King Hussein Cancer Center, Amman, Jordan; ${ }^{5}$ Office of Scientific Affairs and Research, King Hussein Cancer Center, Amman, Jordan
\end{abstract}

Correspondence: Hikmat Abdel-Razeq Department of Internal Medicine, King Hussein Cancer Center, Queen Rania Al Abdullah Street, P.O. Box 1269, Amman II94I, Jordan

Tel +96265300460 Ext 1000

Email habdelrazeq@khcc.jo
Purpose: Compared to Western societies, breast cancer diagnosis in our region is usually made at a younger age and at a more advanced stage. Breast cancer in younger patients tends to be more aggressive, and may result in a higher likelihood of long-term treatment-related toxicity and unique psychosocial problems. This study highlights the clinicopathological features and treatment outcomes in this age-group in a developing country like ours.

Methods: Consecutive patients aged 40 years or younger with a pathologically confirmed diagnosis of breast cancer treated and followed up at our institution were included. Medical records and hospital databases were searched for patients' characteristics and treatment outcomes.

Results: A total of 417 patients were enrolled. Median age at diagnosis was 35 (21-40) years. On presentation, 63 (15.1\%) patients had metastatic disease, $50(79.4 \%)$ with visceral metastasis. Patients with nonmetastatic disease had poor pathological features, including node-positivity $(66.9 \%)$, grade III (51.4\%), lymphovascular invasion $(48.6 \%)$ and positive HER2 (31.5\%). Breast-conserving surgery was performed on $32.9 \%$, and only $36.5 \%$ of women had breast-reconstruction surgery. At a median follow-up of 59 months, 5-year overall survival for the whole group was $72 \%$ : $84 \%$ for nonmetastatic and $13 \%$ for those with metastatic disease. On Cox regression, nodal metastasis (adjusted HR 3.46, 95\% CI $1.48-8.10 ; p=0.004)$ and grade III disease (HR 1.97, 95\% CI 1.14-3.39; $p=0.015$ ) were associated with poor outcome.

Conclusion: Adolescents and young Jordanian adults with breast cancer present with more advanced-stage disease and more aggressive pathological features that reflect poorly on treatment outcomes.

Keywords: breast cancer, adolescents and young adults, AYA, developing countries, late presentation

\section{Introduction}

Breast cancer remains the most common cancer among women. In Jordan and many neighboring countries, breast cancer tends to be diagnosed at an earlier age than elsewhere. As reported by the Jordanian Cancer Registry, the median age at diagnosis has not changed over the last 12 years and remains at 50-51 years. ${ }^{1}$ The latest report published by the registry indicated that a total of 178 breast cancer cases were reported among women aged $<40$ years, representing $33.3 \%$ of all cancers in this age-group and $15.2 \%$ of all breast cancer cases among all age-groups. ${ }^{2}$ In the US, only $6.6 \%$ (10\% among blacks and $5 \%$ of whites) of all female breast cancers are diagnosed in women aged $<40$ years. $^{3,4}$ 
Breast cancer in younger patients tends to be more aggressive, ${ }^{5-9}$ leading to worse outcomes and a need for more aggressive treatment, which may result in a higher likelihood of long-term treatment-related toxicity and unique psychosocial problems. ${ }^{10}$ Additionally, familial predisposition to breast cancer, like BRCA1 and BRCA2 mutations, is more common in this age-group. Given the high penetrance rates among such mutation carriers, ${ }^{11,12}$ it is extremely important to identify patients who may need additional risk-reduction interventions like bilateral mastectomies and oophorectomies.

Breast reconstruction following surgery in the diseased breast or the unaffected one improves quality of life and enhances patients' body image, especially in this agegroup. A multidisciplinary team approach is much needed to address logistics, including full psychosocial support, which should also address financial costs, as such reconstructive procedures and prophylactic surgeries are not usually covered by local private and governmental healthinsurance plans.

\section{Methods}

Consecutive patients aged 40 years or younger with a pathologically confirmed diagnosis of breast cancer treated and followed up at our institution between January 2006 and September 2013 were included. Medical records and hospital databases were searched for patients' characteristics, treatment offered, and outcomes. A total of 21 patients were excluded because of lack of follow-up. All non-Jordanian patients were excluded as well. To ensure adequate follow up, we included patients diagnosed through 2013. Data on tumor stage, type of surgery, systemic chemotherapy, radiation therapy, tumor recurrence, and death were collected through chart review. Data related to tumor size, histological type, lymph-node status and number of metastatic lymph nodes were obtained directly from the pathology report. All patients had had their pathology reviewed at our institution. Vital status and death dates were confirmed using a national civil department database. Patients were treated on institutional unified clinical practice guidelines based on standard international ones. Trastuzumab was offered in both neoadjuvant (since January 2012) or adjuvant (since January, 2008) settings. Endocrine treatment was tamoxifen and was offered for 5 years. However, aromatase inhibitors and GnRH agonists were also offered for highrisk patients aged 36 years or younger. Table 1 details the chemotherapy and anti-HER2 and endocrine therapy
Table I Chemotherapy Regimens

\begin{tabular}{|c|c|}
\hline \multirow[t]{4}{*}{ Adjuvant* } & AC every 3 weeks $\times 4$ cycles \\
\hline & $\begin{array}{l}\text { AC every } 3 \text { weeks for } 4 \text { cycles followed by } \\
\text { weekly paclitaxel } \times 12 \text { weeks }\end{array}$ \\
\hline & $\begin{array}{l}\text { FEC every } 3 \text { weeks } \times 3 \text { cycles followed by } \\
\text { docetaxel every } 3 \text { weeks } \times 3 \text { cycles }\end{array}$ \\
\hline & $\begin{array}{l}\text { Paclitaxel } \times 12 \text { weeks followed by FEC } \\
\text { every } 3 \text { weeks } \times 3 \text { cycles }\end{array}$ \\
\hline Neoadjuvant ${ }^{\wedge}$ & $\begin{array}{l}\text { AC every } 3 \text { weeks } \times 4 \text { cycles followed by } \\
\text { docetaxel every } 3 \text { weeks } \times 4 \text { cycles } \\
\text { (NSABP-B27) }\end{array}$ \\
\hline \multirow{10}{*}{$\begin{array}{l}\text { Chemotherapy for } \\
\text { metastatic disease }^{\#}\end{array}$} & AC every 3 weeks (maximum 6 cycles) \\
\hline & Docetaxel every 3 weeks till best response \\
\hline & Paclitaxel weekly \\
\hline & Capecitabine \\
\hline & Capecitabine + docetaxel \\
\hline & Gemcitabine \\
\hline & Vinorelbine \\
\hline & Cisplatin + gemcitabine \\
\hline & Carboplatin + paclitaxel \\
\hline & Erbulin \\
\hline
\end{tabular}

Notes: *If HER2/Neu-positive, trastuzumab with taxanes added. 'If HER2/neupositive, trastuzumab and pertuzumab added. " If HER2/Neu-positive, trastuzumab and/or pertuzumab added based on protocol.

Abbreviations: AC, adriamycin-cyclophosphamide; FEC, 5-flurouracil-epirubicincyclophosphamide.

given. The study was approved by the institutional review board at King Hussein Cancer Center. Data collection and review of medical records were performed in accordance with the ethical standards of the board and the 1964 Declaration of Helsinki and its later amendments. Because of the retrospective nature of our study and lack of patient identification, informed consent was waived for all participants involved in the study.

\section{Statistical Analysis}

Follow-up duration was calculated from the date of diagnosis until the date of death or last clinical follow-up. The median follow up was 59 (39-148) months. Survival rates were calculated using life-table methods. Disease-free survival (DFS) and overall survival (OS) rates were obtained at 5 years. Throughout our paper, "metastatic disease" refers to those with bone or visceral metastasis. Those with regional 
lymph-node metastasis are included in the "nonmetastatic" group. Survival curves were presented using the KaplanMeier method, and the significance of differences in median survival duration between groups was assessed using logrank tests. OS was estimated from the date of diagnosis to the date of death from any cause. DFS was calculated from the date of diagnosis to date of locoregional recurrence or distant metastasis. For multivariate analysis of OS and DFS in non-metastatic patients, Cox proportional-hazard regression models were used. Covariates that were significantly associated with OS and/or DFS in the univariate analyses were included in the final models. HRs 95\% CIs were calculated for all factors in the multivariate models. Statistical significance was set at $p \leq 0.05$ for each analysis.

\section{Results}

A total of 417 patients with a pathologically confirmed diagnosis of breast cancer were included. All patients were treated and followed up at our institution. The median age at diagnosis was 35 (21-40) years. First-degree family history of breast cancer was reported by $72(17.3 \%)$ patients, and an additional 20 (4.8\%) had first-degree family relative(s) with other cancer(s) like ovarian, endometrium, and prostate cancers. Patients were evaluated and followed up in our breast cancer genetic-counseling clinic and most underwent $B R C A 1$ and $B R C A 2$ testing, the results of which have previously been reported by our group. ${ }^{13}$

On presentation 63 (15.1\%) patients had metastatic disease: 50 (79.4\%) with visceral metastasis including the liver, lung, and brain, and $13(20.6 \%)$ bone-only metastasis. Many of the 354 patients with nonmetastatic disease had poor clinical and pathological features, including 237 (66.9\%) with positive axillary lymph nodes, 182 $(51.4 \%)$ with grade III, $100(28.2 \%)$ with T3 or T4 disease, and 172 (48.6\%) with positive lymphovascular invasion. Both estrogen receptors (ERs) and progesterone receptors (PRs) were positive in 284 (68.1\%) patients, while $52(12.5 \%)$ others had ER- or PR-positive disease and $80(19.2 \%)$ had hormone receptor-negative disease. Not all patients had been tested for HER2; however, 122 (31.5\%) of the 387 those tested patients were HER2positive on immunohistochemical staining or fluorescence in situ hybridization. However, only 37 (9.6\%) patients had triple-negative disease (Table 2).

A total of $353(84.7 \%)$ underwent surgical resection of the tumor, $116(32.9 \%)$ breast-conserving surgery, and $95(26.9 \%)$ skin-sparing or skin-sparing plus nipplesparing mastectomy, while 142 (40.2\%) underwent
Table 2 Patient Characteristics $(n=4 \mid 7)$

\begin{tabular}{|c|c|c|c|}
\hline & & Number & Percentage \\
\hline Age, years & $\begin{array}{l}21-25 \\
26-30 \\
31-35 \\
36-40\end{array}$ & $\begin{array}{l}14 \\
59 \\
137 \\
207\end{array}$ & $\begin{array}{l}3.4 \% \\
14.1 \% \\
32.8 \% \\
49.6 \%\end{array}$ \\
\hline \multirow{2}{*}{$\begin{array}{l}\text { Family history } \\
\text { (first-degree) }\end{array}$} & Breast cancer & 72 & $17.3 \%$ \\
\hline & Other cancers & 20 & $4.8 \%$ \\
\hline Histology & $\begin{array}{l}\text { IDC } \\
\text { ILC } \\
\text { Others }\end{array}$ & $\begin{array}{l}386 \\
20 \\
11\end{array}$ & $\begin{array}{l}92.6 \% \\
4.8 \% \\
2.6 \%\end{array}$ \\
\hline Tumor size* & $\begin{array}{l}\text { TI } \\
\text { T2 } \\
\text { T3 } \\
\text { T4 } \\
\text { Tx }\end{array}$ & $\begin{array}{l}92 \\
161 \\
79 \\
21 \\
1\end{array}$ & $\begin{array}{l}26 \% \\
45.5 \% \\
22.3 \% \\
5.9 \% \\
0.28 \%\end{array}$ \\
\hline Lymph node* & $\begin{array}{l}\text { Negative } \\
\text { Positive }\end{array}$ & $\begin{array}{l}117 \\
237\end{array}$ & $\begin{array}{l}33.1 \% \\
66.9 \%\end{array}$ \\
\hline Stage & $\begin{array}{l}\text { I } \\
\text { II } \\
\text { III } \\
\text { IV }\end{array}$ & $\begin{array}{l}47 \\
158 \\
149 \\
63\end{array}$ & $\begin{array}{l}11.3 \% \\
37.9 \% \\
35.7 \% \\
15.1 \%\end{array}$ \\
\hline Grade* & $\begin{array}{l}\text { I } \\
\text { II } \\
\text { III } \\
\text { Unknown }\end{array}$ & $\begin{array}{l}9 \\
163 \\
182 \\
1\end{array}$ & $\begin{array}{l}2.5 \% \\
46 \% \\
51.4 \%\end{array}$ \\
\hline $\begin{array}{l}\text { Lymphovascular } \\
\text { invasion* }\end{array}$ & $\begin{array}{l}\text { Positive } \\
\text { Negative } \\
\text { Unknown }\end{array}$ & $\begin{array}{l}172 \\
180 \\
2\end{array}$ & $\begin{array}{l}48.6 \% \\
50.8 \% \\
0.56 \%\end{array}$ \\
\hline \multirow[t]{4}{*}{$\begin{array}{l}\text { Hormone } \\
\text { receptors }\end{array}$} & $\begin{array}{l}\text { ER-positive-PR- } \\
\text { positive }\end{array}$ & 284 & $68.1 \%$ \\
\hline & $\begin{array}{l}\text { ER-positive-/PR- } \\
\text { negative }\end{array}$ & 32 & $7.7 \%$ \\
\hline & $\begin{array}{l}\text { PR-positive-ER- } \\
\text { negative }\end{array}$ & 20 & $4.8 \%$ \\
\hline & $\begin{array}{l}\text { ER-negative-PR- } \\
\text { negative }\end{array}$ & 80 & $19.2 \%$ \\
\hline HER2 ${ }^{\#}$ & $\begin{array}{l}\text { Positive } \\
\text { Negative } \\
\text { NA }\end{array}$ & $\begin{array}{l}122 \\
265 \\
30\end{array}$ & $\begin{array}{l}31.5 \% \\
68.5 \% \\
7.8 \%\end{array}$ \\
\hline \multicolumn{2}{|l|}{ Triple-negative ${ }^{\#}$} & 37 & $9.6 \%$ \\
\hline
\end{tabular}

Notes: *From the 354 patients with nonmetastatic disease; ${ }^{\#}$ from the 387 with known HER2 status.

modified radical mastectomy. Reconstruction procedures were performed on 129 (36.5\%) of 353 patients who underwent surgery: 103 (79.8\%) were immediate, while 
$26(20.2 \%)$ had delayed reconstruction. Among the 224 patients who had no reconstruction, $56(25.0 \%)$ had $\mathrm{T} 1$ disease and $102(45.5 \%)$ T2. Axillary management included sentinel lymph-node biopsy in 77 (21.8\%), sentinel lymph-node biopsy followed by axillary dissection in $44(12.5 \%)$, and upfront axillary dissection in 232 (65.7\%). Among nonmetastatic patients, 91 (25.7\%) had neoadjuvant chemotherapy (four cycles of adriamycin followed by fourmore cycles of docetaxel every 3 weeks) ${ }^{14,15}$ and $258(72.9 \%)$ patients received adjuvant chemotherapy.

Five-year OS data are shown in Figure 1. Across all stages, 5-year OS was $72 \%$ and median OS not reached. Women with stage IV disease had much worse outcomes, with 5 -year OS of $13 \%$ and median survival of 29.2

A

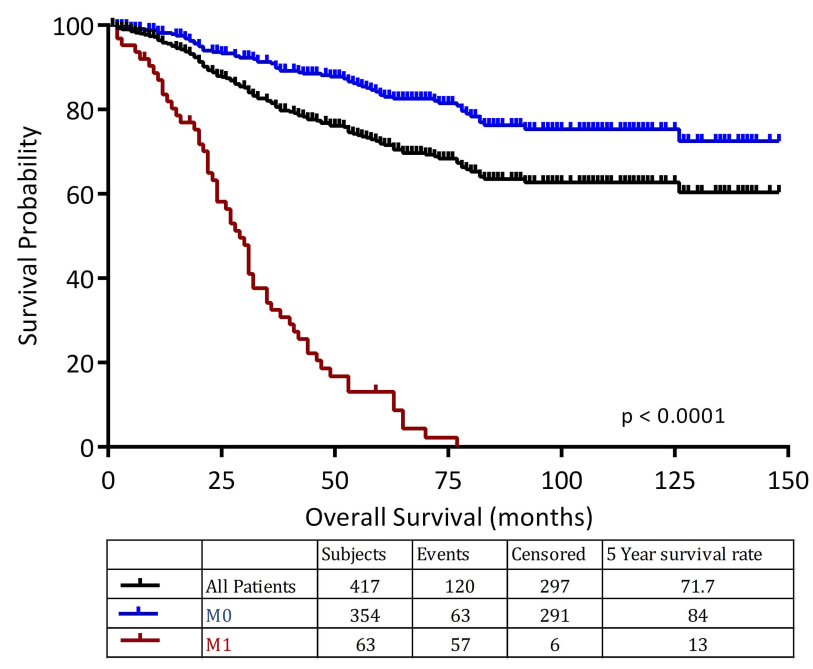

C

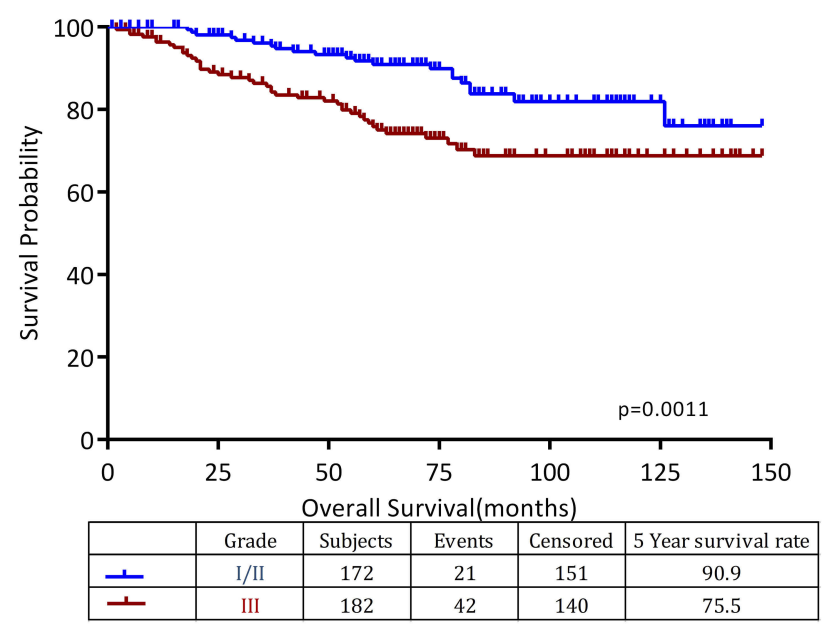

(95\% CI 22.8-32.5) months, while those with nonmetastatic disease had 5-year OS of $84 \% \quad(p<0.0001$, Figure 1A). In patients with nonmetastatic disease, those with node-negative disease had better 5-year OS $(93 \%)$ than those with node-positive disease $(81 \%$, $p=0.0006$, Figure 1B). Likewise, patients with lowgrade disease (GI and GII) had better 5-year OS (91\%) than those with G-III disease $(76 \%, p=0.001$, Figure $1 \mathrm{C})$. We also compared treatment outcomes for younger patients (30 years or younger) to those aged $>30$ years. Although 5-year OS was worse for the younger group (75\% compared to $85 \%$ for those aged $>30$ years, Figure 1D), the difference was not significant ( $p=0.108$ ).

DFS showed similar trends (Figure 2). Lymph-node status (negative versus positive) but not tumor grade (GI/II versus

\section{B}

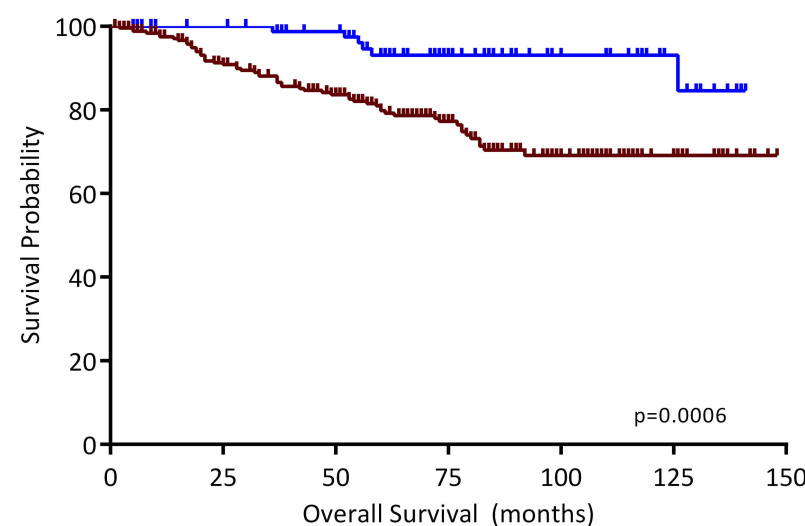

\begin{tabular}{|c|l|c|c|c|c|}
\hline & Nodal Mets & Subjects & Events & Censored & 5 Year survival rate \\
\hline $\boldsymbol{十}$ & Negative & 95 & 6 & 89 & 93.1 \\
\hline $\boldsymbol{十}$ & Positive & 259 & 57 & 202 & 80.6 \\
\hline
\end{tabular}

D

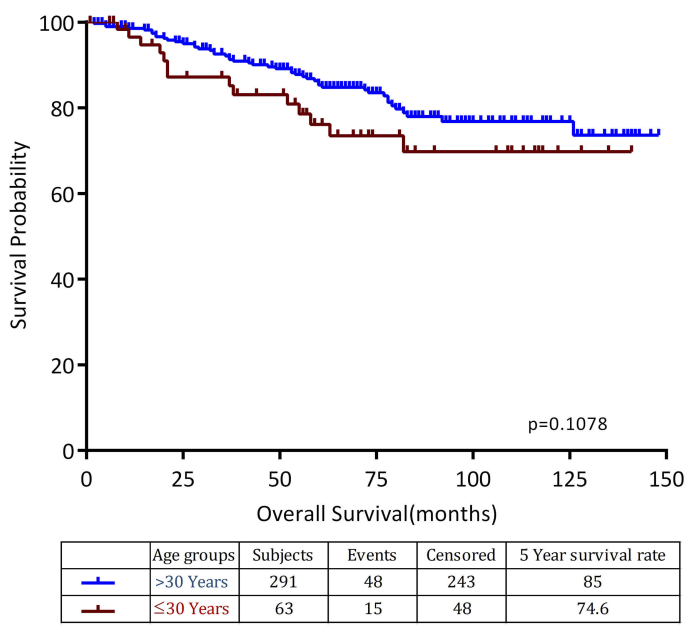

Figure I Overall survival ( $\mathrm{n}=4 \mathrm{I}$ ). (A) Whole group (M0 and MI); (B) node-positive versus node-negative (M0 patients); (C) grade I/II versus grade-III (M0 patients); (D) age $>30$ versus $\leq 30$ years (M0 patients). 
A

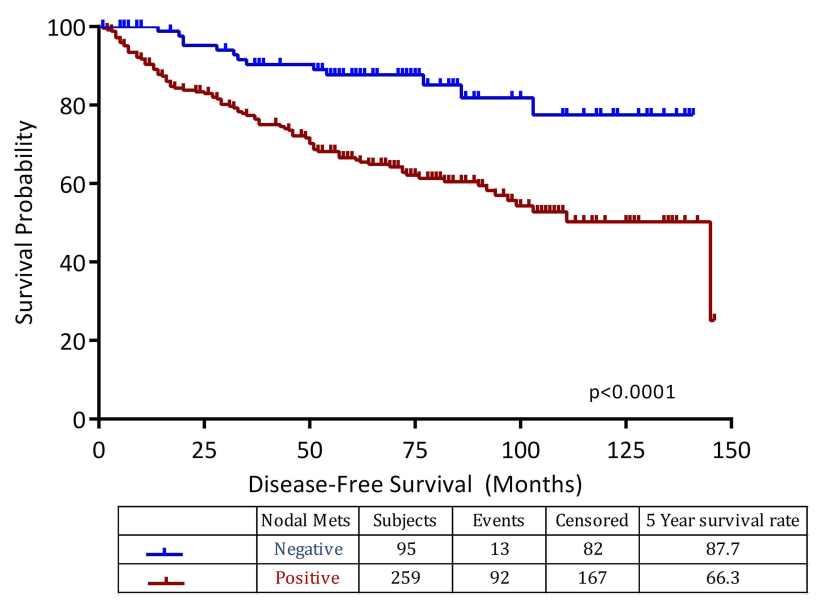

B

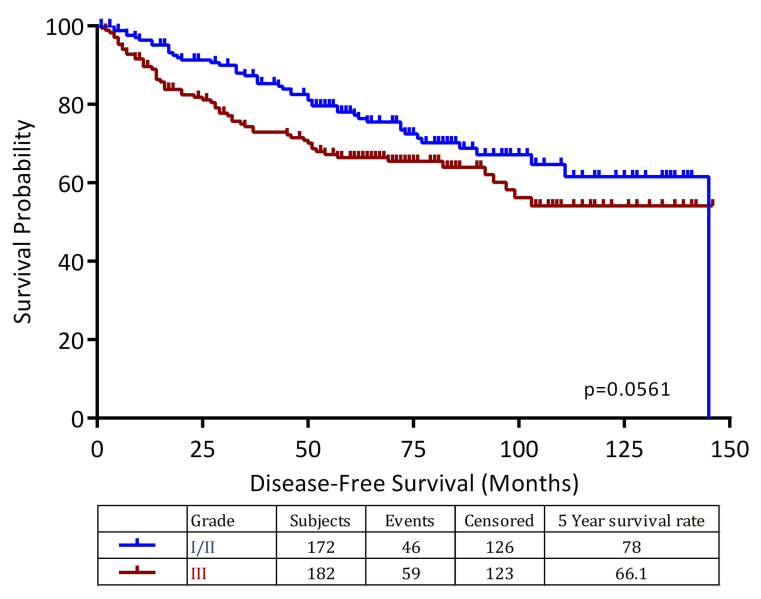

C

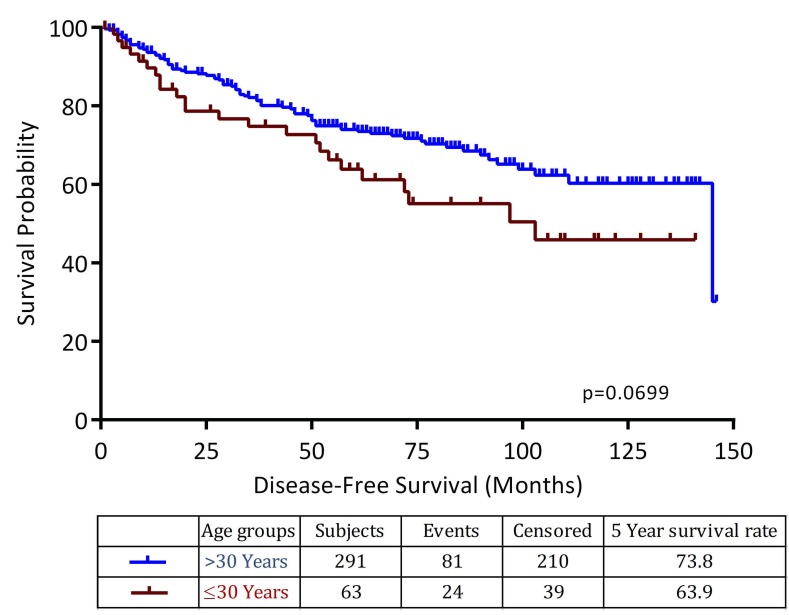

Figure 2 Disease-free survival for the nonmetastatic patients $(n=354)$. (A) Nodepositive versus node-negative; (B) grade I/II versus grade III; (C) age $>30$ versus $\leq 30$ years.

GIII) or age ( $>30$ versus $\leq 30$ years) were associated with better DFS. Multivariate Cox regression analysis for OS (Table 3)
Table 3 Cox Regression, Overall Survival

\begin{tabular}{|l|l|l|l|l|l|}
\hline \multicolumn{2}{|l|}{} & P-value & HR & \multicolumn{2}{l|}{$95 \%$ CI } \\
\hline Nodal metastasis & Positive & 0.0043 & 3.46 & 1.48 & 8.10 \\
Lymphovascular invasion & Positive & 0.0418 & 1.72 & 1.02 & 2.90 \\
Triple-negative & Yes & 0.0179 & 2.36 & 1.16 & 4.81 \\
Grade & III & 0.0150 & 1.97 & 1.14 & 3.39 \\
\hline
\end{tabular}

revealed that nodal metastasis (adjusted HR 3.46, 95\% CI 1.48-8.10; $p=0.004$ ), GIII disease (adjusted HR 1.97, 95\% CI $1.14-3.39 ; p=0.015$ ), and lymphovascular invasion (adjusted HR $1.72,95 \%$ CI $1.02-2.90 ; p=0.042$ ) were independent prognostic factors for OS in nonmetastatic patients. DFS analysis (Table 4) revealed that nodal metastasis (adjusted HR 2.64, 95\% CI 1.46-4.76; $p=0.0012$ ) and lymphovascular invasion (adjusted HR 1.54, 95\% CI 1.03-2.29; $p=0.035$ ) were associated with poor PFS in nonmetastatic breast cancer patients, while GIII disease was not significantly associated with PFS $(p=0.079)$.

\section{Discussion}

Breast cancer in developing countries, like ours, is associated with peculiar features that are not usually encountered in Western societies. First, median age at diagnosis is at least 10 years younger than that of the West, a fact that needs to be taken into consideration when designing early-detection programs and also dealing with psychosocial consequences and long-term treatment complications in a younger age-group. Second, a significant percentage of patients present with locally advanced or metastatic disease, even among the youngest. Of the patients included in this study, 15\% had GIV disease at diagnosis. This rate is significantly higher than what had been reported in Western literature. In one study that included 185 patients aged 30 years and younger at the MD Anderson Cancer Center almost 20 years ago, only $6 \%$ presented with GIV disease. ${ }^{16}$ This is not related to referral bias: data published by our national cancer registry confirmed this pattern too. ${ }^{2}$

Our study illustrates special clinical and pathological features among this age-group that reflect negatively on their treatment outcomes. Two-thirds of our patients presented

Table 4 Cox Regression, Disease-Free Survival

\begin{tabular}{|l|l|l|l|l|l|}
\hline \multicolumn{2}{|l|}{} & P-value & HR & \multicolumn{2}{|c|}{$95 \%$ CI } \\
\hline Nodal metastasis & Positive & 0.0012 & 2.64 & 1.46 & 4.76 \\
Lymphovascular invasion & Positive & 0.0349 & 1.54 & 1.03 & 2.29 \\
Grade & III & 0.0791 & 1.42 & 0.96 & 2.10 \\
\hline
\end{tabular}


with node-positive disease, and $>50 \%$ had high-grade (GIII) disease. Additionally, HER2/Neu overexpression was detected in almost a third of patients, much higher than the 15\%-20\% reported by many others. ${ }^{17}$ It is known that HER2/Neu positivity correlates with a worse histological and nuclear grade, lower rate of ER/PR expression, higher rate of proliferation and poor prognosis. ${ }^{18}$

Another point that deserves highlighting here is the low rate of breast-reconstruction procedures performed in our patients. Despite being that young, only a third of the patients with early-stage disease underwent immediate or delayed breast reconstruction. Even those with small tumors, T1 and T2 disease, had not done so. While cultural differences do exist and body image might not be perceived the same across different cultures and nations, other factors might have contributed to this low rate. Financial coverage could have been a barrier, as such procedures are not totally covered by insurance. In-depth analysis and future studies are needed to understand needs and barriers further.

Across all stages and subtypes, breast cancer survival rates are comparatively lower for women aged $<40$ years of age than for older women. ${ }^{19-23}$ Additionally, the significant improvement in treatment outcomes witnessed in recent years for breast cancer has not been at the same magnitude in younger patients. Despite the limited resources and the increasing cost of breast cancer therapy, our survival data in this particular age-group are similar to what has been published in the West. In the MD Anderson Cancer Center study mentioned previously, the 5-year OS rate was $87 \%$ for patients with G I disease, $60 \%$ for GII, $42 \%$ for GIII, and $16 \%$ for GIV. ${ }^{16}$

Few additional points need to be stressed during the care of breast cancer in this age-group. Much of the treatment offered, both chemotherapy and endocrine therapy, may have a significant negative impact on fertility that needs to be addressed and taken into consideration, even before initiation of treatment. ${ }^{24}$ Furthermore, given the high prevalence of hereditary predisposition to breast cancer and its associated medical and psychosocial consequences, such patients need to be treated in comprehensive cancer centers that can deal with these issues. ${ }^{25}$

Though our study is a single-institution one, our center treats over two-thirds of all breast cancer patients in the country and most of the others are treated with our own protocols. In summary, adolescents and young Jordanian adults with breast cancer present with more advanced-stage disease and more aggressive pathological features that reflect poorly on their treatment outcomes. Such findings, along with our own demographics and population pyramid, should help us design a more aggressive approach and strategies toward early breast cancer detection and awareness programs in this age-group.

\section{Disclosure}

The authors report no conflicts of interest in this work.

\section{References}

1. Al-Sayaideh A, Nimri O, Arqoub K, Al-Zaghal M, Halasa W. Cancer Incidence in Jordan-2012. Ministry of Health, Non-Communicable Diseases Directorate, Jordan Cancer Registry; 2012. Available from: http://www.moh.gov.jo/Echobusv3.0/SystemAssets/a05a084b-37814979-a217-2184d5d57ede.pdf. Accessed July 26, 2019.

2. Jordan Cancer Registry. Cancer incidence in Jordan. 2015. Available from: http://www.moh.gov.jo/Pages/viewpage.aspx?pageID=240. Accessed July $05,2019$.

3. Johnson E. Breast cancer racial differences before age 40-implications for screening. J Nat Med Assoc. 2002;94:149-156.

4. Korde LA, Partridge AH, Esser M, Lewis S, Simha J, Johnson RH. Breast cancer in young women: research priorities. A report of the young survival coalition research think tank meeting. J Adolesc Young Adult Oncol. 2015;4(1):34-43. doi:10.1089/jayao.2014.0049

5. Rosenberg SM, Partridge AH. Management of breast cancer in very young women. Breast. 2015;24(Suppl 2):S154-S158. doi:10.1016/j. breast.2015.07.036

6. Hironaka-Mitsuhashi A, Tsuda H, Yoshida M, et al. Invasive breast cancers in adolescent and young adult women show more aggressive immune-histochemical and clinical features than those in women aged 40-44 years. Breast Cancer. 2019;26(3):386-396. doi:10.1007/ s12282-018-00937-0

7. Anders CK, Hsu DS, Broadwater G, et al. Young age at diagnosis correlates with worse prognosis and defines a subset of breast cancers with shared patterns of gene expression. J Clin Oncol. 2008;26 (20):3324-3330. doi:10.1200/JCO.2007.14.2471

8. Collins LC, Marotti JD, Gelber S, et al. Pathologic features and molecular phenotype by patient age in a large cohort of young women with breast cancer. Breast Cancer Res Treat. 2012;131(3):1061-1066. doi:10.1007/s10549-011-1872-9

9. Hartley MC, McKinley BP, Rogers EA, et al. Differential expression of prognostic factors and effect on survival in young $(<$ or =40) breast cancer patients: a case-control study. Am Surg. 2006;72(12):1189-1194.

10. Fernandes-Taylor S, Adesoye T, Bloom JR. Managing psychosocial issues faced by young women with breast cancer at the time of diagnosis and during active treatment. Curr Opin Support Palliat Care. 2015;9(3):279-284. doi:10.1097/SPC.0000000000000161

11. Chen S, Parmigiani G. Meta-analysis of BRCA1 and BRCA2 penetrance. J Clin Oncol. 2007;25(11):1329-1333. doi:10.1200/ JCO.2006.09.1066

12. Mavaddat N, Peock S, Frost D, et al. EMBRACE. Cancer risks for BRCA1 and BRCA2 mutation carriers: results from prospective analysis of EMBRACE. J Natl Cancer Inst. 2013;105(11):812-822. doi:10.1093/jnci/djt095

13. Abdel-Razeq H, Al-Omari A, Zahran F, Arun B. Germline BRCA1/ BRCA2 mutations among high risk breast cancer patients in Jordan. BMC Cancer. 2018;18(1):152. doi:10.1186/s12885-018-4079-1

14. Abdel-Razeq H, Marei L, Saadeh SS, et al. From clinical trials to clinical practice: outcome of NSABP-B27 neoadjuvant chemotherapy regimen for high-risk early-stage breast cancer. Breast Cancer Res Treat. 2017;165(3):771-777. doi:10.1007/s10549-017-4359-5 
15. Abdel-Razeq H, Saadeh SS, Abu-Nasser M, et al. Four cycles of adriamycin and cyclophosphamide followed by four cycles of docetaxel (NSABP-B27) with concomitant trastuzumab as neoadjuvant therapy for high-risk, early-stage, HER2-positive breast cancer patients. Onco Targets Ther. 2018;11:2091-2096. doi:10. 2147/OTT

16. Xiong Q, Valero V, Kau V, et al. Female patients with breast carcinoma age 30 years and younger have a poor prognosis: the M.D. Anderson Cancer Center experience. Cancer. 2001;92:2523-2528. doi:10.1002/(ISSN)1097-0142

17. Noone AM, Cronin KA, Altekruse SF, et al. Cancer incidence and survival trends by subtype using data from the surveillance epidemiology and end results program, 1992-2013. Cancer Epidemiol Biomarkers Prev. 2017;26:632-641. doi:10.1158/1055-9965.EPI-160520

18. Sjögren S, Inganäs $\mathrm{M}$, Lindgren $\mathrm{A}$, et al. Prognostic and predictive value of c-erbB-2 overexpression in primary breast cancer, alone and in combination with other prognostic markers. $J$ Clin Oncol. 1998;16:462-469. doi:10.1200/JCO.1998.16.2.462

19. Sheridan W, Scott T, Caroline S, et al. Breast cancer in young women: have the prognostic implications of breast cancer subtypes changed over time? Breast Cancer Res Treat. 2014;147(3):617-629. doi:10.1007/s10549-014-3125-1
20. Ribnikar D, Ribeiro JM, Pinto D, et al. Breast cancer under age 40 : a different approach. Curr Treat Options Oncol. 2015;16(4):16. doi:10.1007/s11864-015-0334-8

21. Kataoka A, Tokunaga E, Masuda N, Shien T, Kawabata K, Miyashita M. Clinicopathological features of young patients $(<35$ years of age) with breast cancer in a Japanese Breast Cancer Society supported study. Breast Cancer. 2014;21(6):643-650. doi:10.1007/ s12282-013-0466-2

22. Cancello G, Maisonneuve P, Rotmensz N, et al. Prognosis and adjuvant treatment effects in selected breast cancer subtypes of very young women (<35 years) with operable breast cancer. Ann Oncol. 2010;21(10):1974-1981. doi:10.1093/annonc/mdq072

23. Kim EK, Noh WC, Han W, Noh DY. Prognostic significance of young age $(<35$ years) by subtype based on ER, PR, and HER2 status in breast cancer: a nationwide registry-based study. World J Surg. 2011;35(6):1244-1253. doi:10.1007/s00268-011-1071-1

24. Lambertini M, Ginsburg ES, Partridge AH. Update on fertility preservation in young women undergoing breast cancer and ovarian cancer therapy. Curr Opin Obstet Gynecol. 2015;27:98-107. doi: $10.1097 / \mathrm{GCO} .0000000000000138$

25. Menen R, Hunt K. Considerations for the treatment of young patients with breast cancer. Breast J. 2016;22(6):667-672. doi:10.1111/ tbj.2016.22.issue-6

\section{Publish your work in this journal}

Cancer Management and Research is an international, peer-reviewed open access journal focusing on cancer research and the optimal use of preventative and integrated treatment interventions to achieve improved outcomes, enhanced survival and quality of life for the cancer patient.
The manuscript management system is completely online and includes a very quick and fair peer-review system, which is all easy to use. Visit http://www.dovepress.com/testimonials.php to read real quotes from published authors. 